\title{
Landscape Evaluation Based on Gaofen Satellite in the Southern Part of the Nile Delta, Egypt
}

\author{
Hazem T. Abd El-Hamid1,2*, Wenlong Wang2, Qiaomin Li \\ ${ }^{1}$ Department of Marine Pollution, National Institute of Oceanography and Fisheries, Alexandria, Egypt \\ ${ }^{2}$ Ningxia Institute of Remote Sensing Surveying and Mapping, Yinchuan, China \\ Email: ^hazem_ecology@yahoo.com
}

How to cite this paper: El-Hamid, H. T. A., Wang, W. L., \& Li, Q. M. (2019). Landscape Evaluation Based on Gaofen Satellite in the Southern Part of the Nile Delta, Egypt. Journal of Geoscience and Environment Protection, 7, 47-60.

https://doi.org/10.4236/gep.2019.77005

Received: June 4, 2019

Accepted: July 21, 2019

Published: July 24, 2019

Copyright $\odot 2019$ by author(s) and Scientific Research Publishing Inc. This work is licensed under the Creative Commons Attribution International License (CC BY 4.0).

http://creativecommons.org/licenses/by/4.0/

\begin{abstract}
Landscape segmentation and classification is fundamental to landscape research because it provides an important frame of reference for researchers to communicate and compare their work. Anthropogenic human activities mainly lead to landscape changes. The present study aims to assess the impact of anthropogenic activities on landscape classification of the Nile Delta using remote sensing and GIS techniques. Field survey, digital databases and GIS capabilities are applied for landscapes classification. Vector data using a lot of maps and raster data using satellite image have the ability to give obvious classification about landscape. Results showed that the anthropogenic impacts affect negatively on the landscape classification. Using GF2, landscapes are classified into major eight classes: cultivated land, garden land, woodland, grassland, bare land, urban land, water bodies and mining land. It was showed that the urban occupies the highest percentage of the study area. Urban construction and development areas centered on the capital Cairo city and the city of Giza are dumbbell-shaped to the east. Bare lands occupy the second percentage of the study area, and it may be distributed on around the Nile Delta, southeast of Cairo City and southwest of Giza City. According to vegetation cover, three classes were applied as the sequence: Cultivated land > Garden land > Grass land. These classes depend mainly on the River Nile. Vegetation cover may be based mainly on the water from the Nile River. In addition, mining land occupies the least percentage of the study area. The main distribution of mines and mineral exploration is also very small, but it is distributed on the edge of the city. Landscape metric as Fractal Dimension (Frac) and the Square Pixel (SqP) was applied to validate the segmentation and classification. These metrics indicated that the landscape classification is related to natural and human changes. These changes were related to unplanned management of new projects and some anthropogenic activities.
\end{abstract}




\section{Keywords}

Landscape, Nil Delta, GIS, Metrics, GF2

\section{Introduction}

Modern technology and negative human activities affect adversely on the nature of the earth surface causing major and minor changes in landscapes. Jackman in 1988 classified the value and importance of landscape into three classes: environmental, ethical and economic. These changes have altered the ecology of the environment and caused environmental degradation, such as desertification, urbanization, salinization, flooding and drought. Previous studies have proven that there has a large relation between human activities and landscape changes in the environment. These changes achieve the increase of the urbanization problem and biodiversity damage. Recently, the landscape of the Nile Delta has been affected by environmental problems especially, urbanization. Rapid changes have occurred abundantly in the area of the Delta Nile in recent years with speed of urbanization and remarkable landscapes changes. It's considered that the Nile Delta is one of the oldest cultivated lands in the surface earth. El-Ramady et al. (2013) stated that the density of population in the sector of Nile Delta is up to 1600 inhabitants per square kilometer. This overpopulation causes severe socioeconomic problems such as high unemployment, undermining rising living standards and crime rate (Shalaby \& Tateishi, 2007). Landscape features may be affected by the changing in the area of every land use in the earth surface. To achieve sustainable development, landscape management should be organized and studied by many stakeholders with the cooperation with the government (Reed et al., 2015). The northern part of the Nile Delta has been carefully cultivated by agriculture crops and some fruits depending on the water of the Nile River, and the southern part of this study typically includes some mountains and bare lands. Currently, this area has become the ideal solution for the development of major cities in Cairo, modern technology and high populations. To achieve sustainable development in Nile Delta, landscape investigation should be studied using various methods. Visual interpretation and digitization of the landscape classes according to the defined nomenclature may be classified into four classes: vegetation, water, urban and wetlands (Topaloglu et al., 2016). Remote sensing using GF2 satellite imagery offers interesting potentials for monitoring and assessing changes in land cover and land use. Environmental studies such as landscape changes may be correctly analyzed and interpreted using new techniques of remote sensing and GIS. Spatial distributions of landscape may explain the unique change in biodiversity of any study area (Rocchini et al., 2006). Visual interpretation of maps with segmentation of images has the potentiality of using remote sensing and GIS techniques for carefully assessing the landscape changes and achieves sustain- 
able development in the future.

\section{Materials and Methods}

\subsection{Study Area}

The study area is typically ranged from longitude $30^{\circ} 43^{\prime} 18.83^{\prime \prime} \mathrm{E}-31^{\circ} 31^{\prime} 40.82^{\prime \prime} \mathrm{E}$ and Latitude $29^{\circ} 46^{\prime} 30.49^{\prime \prime} \mathrm{N}-30^{\circ} 21^{\prime} 53.84^{\prime \prime} \mathrm{N}$. It is conveniently located in the center of Egypt capital (Cairo). It is about $66 \mathrm{~km}$ long from north to south and $78 \mathrm{~km}$ wide from east to west, with a total area of more than $5000 \mathrm{~km}^{2}$ as shown in Figure 1. It typically includes Qalyubia and Giza cities. The suitable terrain is low, the soil is fertile and the river network is vertical and horizontal. It is the birthplace of ancient Egyptian civilization. It is occupied by the most populated governorates in Egypt, whereas around 50\% of the populations live in the Nile Delta (Haars et al., 2016). In the south, the cultivated land on both sides of the Nile River canyon is sufficiently developed. The rest of the area is mostly deserted and low mountain areas with hot climate. The climatic condition of this area is almost the climate of the Mediterranean Sea. The climate is hot and dry, the light is strong, and the water source is sufficient. The temperature in winter ranged from $9^{\circ} \mathrm{C}$ to $19^{\circ} \mathrm{C}$, and the average temperature in summer is $22^{\circ} \mathrm{C}$ $34^{\circ} \mathrm{C}$. The average annual precipitation is $50-200 \mathrm{~mm}$.

\subsection{Data Source Selection and Preprocessing}

GF2 satellite data was arbitrarily selected as the main data source and the
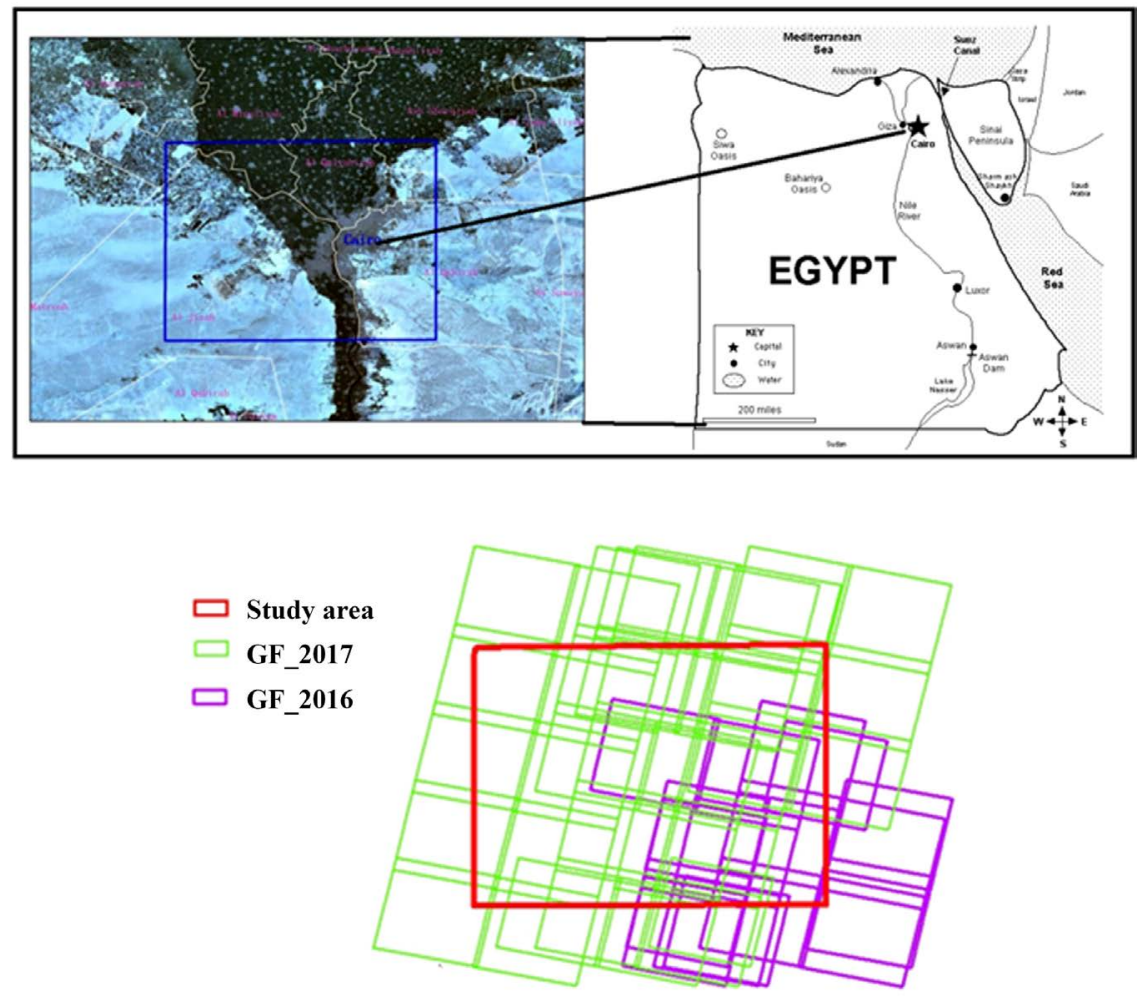

Figure 1. Location map of the study area with raster data (grids). 
non-coverage area was supplemented by the high score GF1 satellite data. Gaofen (GF) is a series of Chinese civilian remote sensing satellites.GF series satellites range from panchromatic, multispectral hyperspectral to optical radar formed an observation system with high spatial resolution, time resolution and spectral resolution, as shown in Table 1. Satellite data was typically acquired in 2016 and 2017. Firstly, radiometric and atmospheric corrections were properly applied. Geometric correction was typically performed for the images with taking the pre-ortho-rectified points using ground control points (GCPs). Then, layer stacked in order to analyze the impact of different seasons on LC/accurate LU classification simultaneously. For further interpretation of landscapes, topographic map with scale 1:100,000 and the National Land Use Survey Classification Standard were applied. According to the regional characteristics of the Nile River Basin in Egypt, the marked degree of interpretation of the surface environmental classes in the work area is carefully analyzed. Landscapes classes of the study area were classified using GF2 into eight classes: cultivated land, garden land, woodland, grassland, bare land, urban land, water bodies and mining land as shown in Table 2 .

\subsection{Landscape Analysis}

Typically based on visual interpretation using ARCGIS 10.5 software, standard classification and social segmentation of classes was performed for landscape analysis. The purpose of the segmentation is to typically create image objects by grouping similar pixels. The best prevalent and widely used segmentation technique is multi-resolution subdivision. In this algorithm, each pixel is considered

Table 1. Characteristics of GF series satellites.

\begin{tabular}{cccc}
\hline Satellite name & \multicolumn{2}{c}{$\mathrm{GF}_{1}$} & $\mathrm{GF}_{2}$ \\
\hline Spatial resolution & $16 \mathrm{~m}$ & $2 \mathrm{~m} / 8 \mathrm{~m}$ & $1 \mathrm{~m} / 4 \mathrm{~m}$ \\
Sensor & WFV & PMS & PMS \\
Width & $800 \mathrm{~km}$ & $70 \mathrm{~km}$ & $45 \mathrm{~km}$ \\
\hline
\end{tabular}

Table 2. Landscapes categories delineated for the classification.

\begin{tabular}{|c|c|}
\hline Class & Description \\
\hline Cultivated land & farmland, ploughland, plowland, tillage and tilled land \\
\hline Garden land & $\begin{array}{l}\text { Land used for the cultivation of flowers, vegetables, herbs, or fruit for food fungus } \\
\text { garden maintained by ants }\end{array}$ \\
\hline Wood land & Forest covers including tree cover along the creeks \\
\hline Grass land & Natural grasslands are areas with herbaceous vegetation \\
\hline Bare land & land that has no buildings on it and is not being used \\
\hline Urban area & $\begin{array}{l}\text { Commercial, and residential areas, and other areas with manmade structure; } \\
\text { roads, railway lines }\end{array}$ \\
\hline Water bodies & Farm dams, sewage ponds \\
\hline Mining land & extraction of valuable minerals or other geological materials from the earth \\
\hline
\end{tabular}


as an image object at first and homogeneous image objects are created by typically combining them with their neighbors in an iterative approach. In this process, five model parameters called size; shape, shadow, color, pattern texture and local association are defined by the user, based on the spatial resolution and spectral characteristics of the data and desired object size. The most important parameter is scale, which directly affects the size of the object (Belgiu et al., 2014). Visual interpretation using correctly these elements is often a part of our daily lives, whether we are conscious of it or not. Examining satellite images on the weather report or following high speed chases by views from a helicopter are all familiar examples of visual image interpretation. Identifying targets in remotely sensed images based on these visual elements allows us to further interpret and analyze. During the social segmentation and classification processes, thematic layers were used as ancillary vector data in order to properly obtain better results for some of the LC/LU classes. As a direct result, obtaining land use information using only satellite image data was not as easy as determining the land cover. However, historic boundaries of these chief objects were deducted from satellite images; therefore, compatibility of thematic layers with satellite image was carefully evaluated.

\subsection{Landscape Interpretation}

In order to typically make a classification of the landscapes within the study areas, the classified images were first geometrically corrected using a nearest neighbour algorithm. Seven elements were tested for further interpretation of landscape in the study area. These elements were applied and tested by international classification standard of the landscapes.

\subsection{Landscape Metrics}

Qualitative and quantitative changes in landscapes depend on shape length and protected area of the landscape (Turner et al., 2001). In order to quantify and carefully monitor landscape characteristics, landscape complexity must be defined and measured using landscape metrics. Patch shape complexity has been measured using Fractal Dimension (Frac). Its value varies between one and two. Man-made and natural interferences can be applied and examined by lower and higher values of this index. Squared or more structured shape (usually man-made), and higher values cautiously approaching two indicate more complex shapes (natural).

$$
\text { Frac }=2 * \ln [(P / 4) / \ln (A)]
$$

where: Frac is the fractal dimension (patch shape complexity measure), $P$ is the patch perimeter, $A$ is the patch area. Frac measures the standard deviation of the patch shape from an area of some reference geometry. In order for perimeter to naturally increase in proportion to area, the shape of the modern boundary of a unique feature must become more complex as area increases. The improved metric, on the other hand, considers the perimeter area relationship for raster data 
structures and normalizes the ratio of the perimeter and area to a value between zero for squares and 1 (maximum perimeter, edge, deviation from that of a perfect square). The Square Pixel index (SqP) can be precisely calculated by the following formula:

$$
\mathrm{SqP}=1-(4 * \sqrt{A / P})
$$

\subsection{Spatial Distribution of Urban Area (Cities)}

For effective spatial distribution of urban area in the Nile Delta, two interpolation methods were applied indiscriminately. It merely provides a critical estimate at an unobserved location of variable $\mathrm{z}$, based on the weighted average of adjacent observed sites within a given area. Inverse Distance Weighting (IDW) is expected substantially that the degree of associations and relationships between neighbors is relative to the unidentified distance between them that can be well-defined as a distance reverse function of every sore point from neighboring points.

\section{Results and Discussion}

\subsection{Visual Interpretation of Landscape in the Study Area}

Modern interpretation of landscapes in the study area may be carefully observed using selected elements that prominently mentioned in the methodology. Cultivated land, garden land, woodland and grassland were shown in Figure 2(a). The climate of the Nile delta is suitable for most cultivated land as grain and cotton. Wheat, cotton, date palm, orange, sugar beet and other agricultural land were also cultivated with the irrigation water from the River Nile. By way of the high-resolution satellite imagery after the true color synthesis, the agricultural land and construction land, wasteland resources and other land boundaries are clear, but it is more difficult to carefully differentiate among the cultivated land, garden land and woodland. In the study area, bare land may be shown in Figure 2(b). According to the Second National Land Use Survey Classification, bare land includes free land, sand, bare rock gravel and other land types. The bare land surfaces in the study area mainly include sandy land and unused land. These land types have clear boundaries and clear types, and belong to a specific type with high degree of interpretation. Bare land in the study area is mostly distributed in the southeast and southwest of the Nile River. There is basically no obvious vegetation cover on the bare land. Now, the bare land surfaces and features in the study area are gradually used for the gradual development and unique construction of the new river irrigated agriculture, urban residential and industrial uses. The study area also contains large area of urban land that occupies by people as shown in Figure 2(c). According to the Second National Land Use Survey Classification Standards, the urban land contains the residential land, transportation land, commercial land, public management and public service land, urban villages, transportation public facilities, airports, tourist sites 


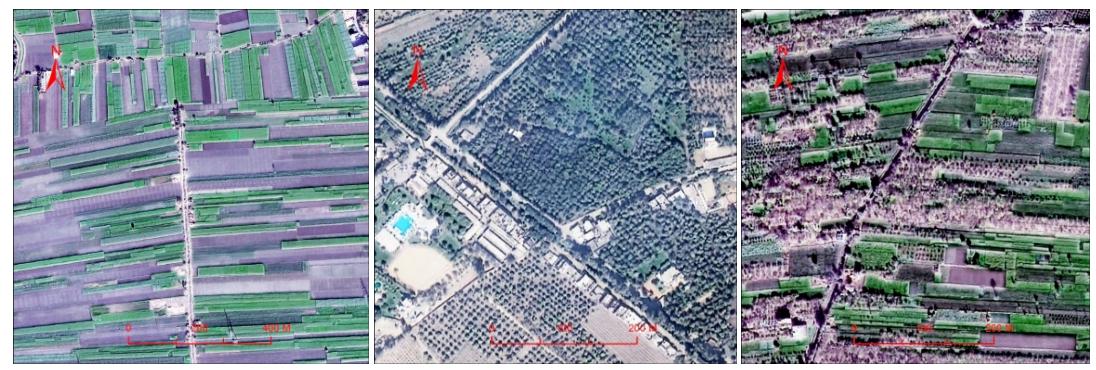

(a)

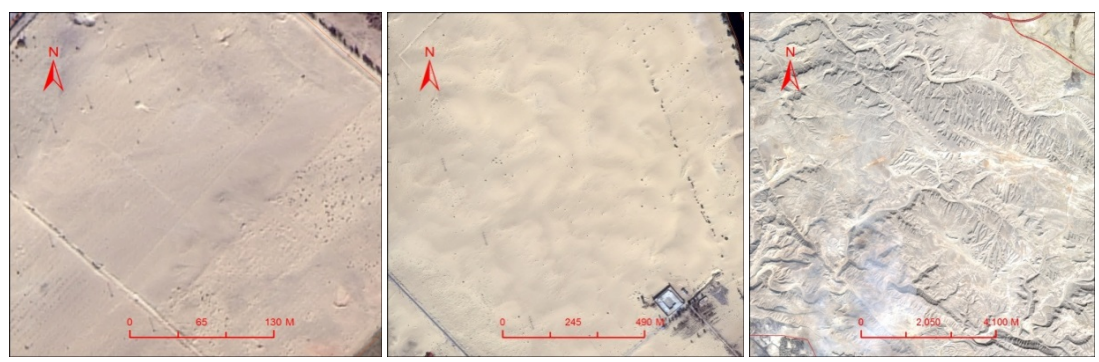

(b)
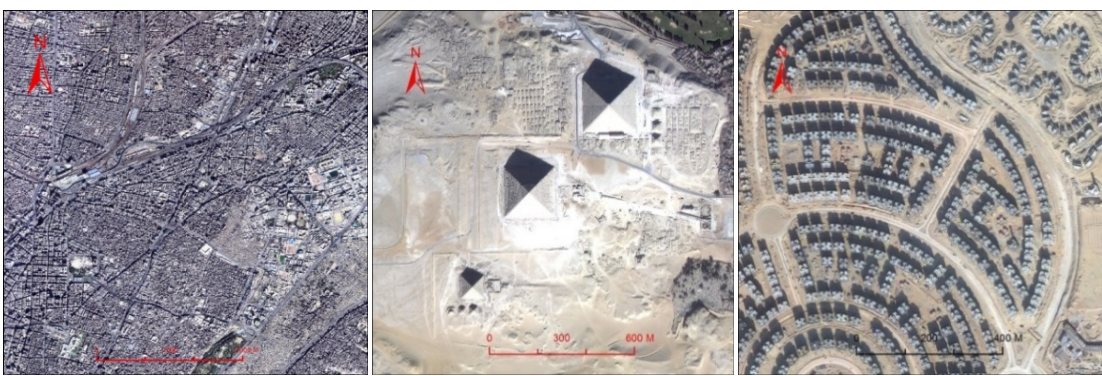

(c)
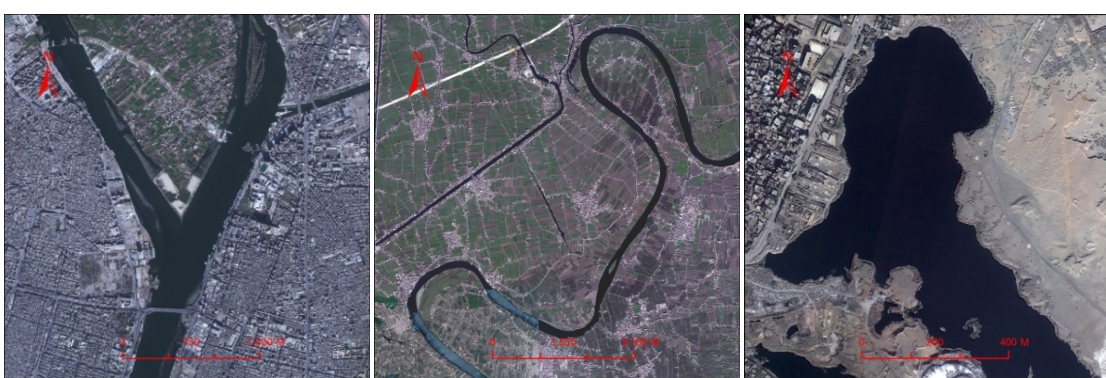

(d)
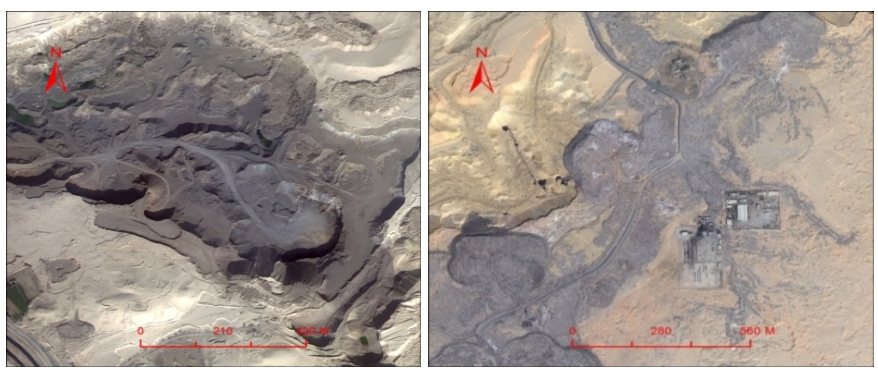

(e)

Figure 2. (a) Visual interpretation of cultivated land, garden land, woodland and grassland; (b) Visual interpretation of bare land; (c) Visual interpretation of urban area; (d) Visual interpretation of water bodies; (e) Visual interpretation of mining land. 
and construction land. The boundaries and the types of attributes of urban land types are clear, and they are easy to identify and interpret. The fundamental problem of urban land may be shown in the interpretation of some construction land. The construction land is complex and scattered, and some construction land is under construction, with obvious construction traces and more construction activities. The surface water in the study area is mainly distributed along Nile River and its grassy ditches, pits and reservoirs in the irrigated area as shown in Figure 2(d). The image features are obvious, the boundary and the attribute type are clear also, the degree of interpretation is high. Finally, small area of the Nile Delta contains some mining industries as shown in Figure 2(e). It is carefully noted through the classification; the proper interpretation of the mining industries in these areas is clearly visible and also erases some of the organic impurities caused by mining operations.

\subsection{Overall Interpretation of Landscapes}

In the present study, eight different landscapes were properly applied using visual interpretation of ARCGIS 10.5 As shown in Figure 3. Area, number of maps and length of landscapes also examined for further interpretation as shown in Table 3 and Figure 4. Interpretation was applied using 7517 maps and about $510,102.80$ hectares of landscapes in the Nile Delta. It was showed that the urban area occupies the largest numbers of maps and the largest area from the study area. The number of maps is about 2766 with area 181,653.23 hectares, with a percentage $35.61 \%$ of the total area of the study area. Urban area is more than one third of the total area of the study area. according to visual interpretation of remote sensing and qualitative density of building, urban area were correctly classified into dense residential areas mainly in cities, new residential areas, villas and new town development areas, and towns and villages. In practical terms of the spatial distribution of construction land, urban and rural construction land is scattered in the agricultural area of the Nile Delta from the south to the north, while the two urban construction and development areas centered on the capital Cairo city and the city of Giza are dumbbell-shaped to the east. The results agreed with Hegazy and Kaloop (2015) that the urban sprawl as a result of rapid population growth as well as the internal migration on the expense of the highest fertile and productive agricultural soil in the Nile Delta. With the construction of
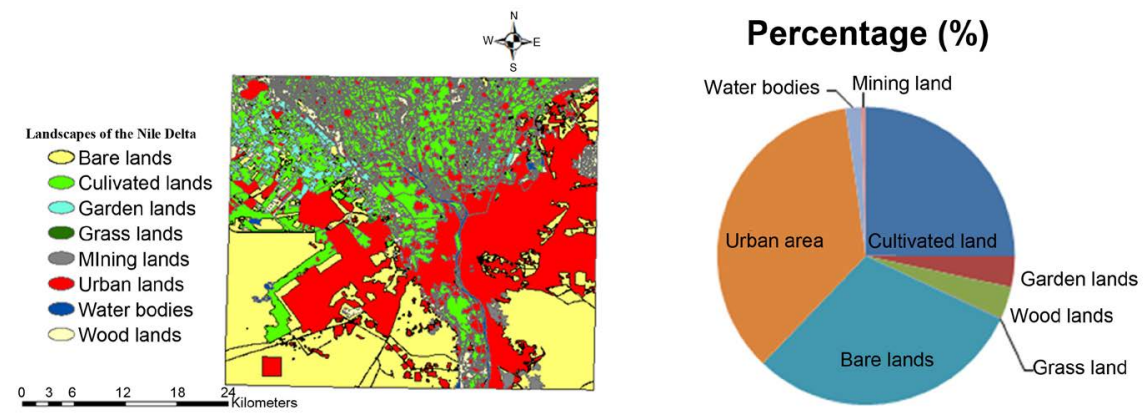

Figure 3. Landscapes distribution with area (hectare) in the study area. 
Table 3. Quantitative evaluation of landscapes of the Nile Delta.

\begin{tabular}{cccccc}
\hline No & Class & No. Maps & Class Length & Area (hectare) & $\%$ \\
\hline 01 & Cultivated land & 2331 & 3125.053 & $127,790.76$ & $25.05 \%$ \\
02 & Garden land & 884 & 2531.421 & $17,041.19$ & $3.34 \%$ \\
03 & Wood land & 705 & 5552.258 & $17,925.60$ & $3.51 \%$ \\
04 & Grass land & 48 & 5076.507 & 386.32 & $0.08 \%$ \\
05 & Bare land & 474 & 3946.403 & $154,031.73$ & $30.20 \%$ \\
06 & Urban area & 2766 & 3608.612 & $181,653.23$ & $35.61 \%$ \\
07 & Water bodies & 291 & 8254.2105 & 8479.53 & $1.66 \%$ \\
08 & Mining land & 18 & $10,268.005$ & 2794.43 & $0.55 \%$ \\
& Total & 7517 & $42,362.47$ & $510,102.80$ & $100.00 \%$ \\
\hline
\end{tabular}

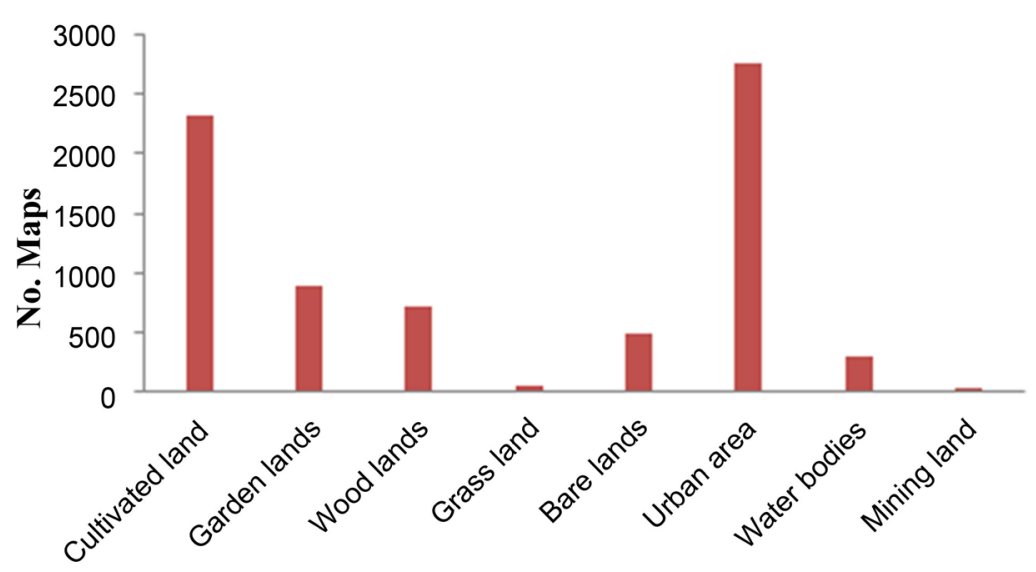

Landscape classes

Figure 4. Distribution of maps for landscapes in the study area.

infrastructure such as roads, railways and airports in cities and towns, the expansion of the capital city of Egypt and the city of Giza gradually develops from the coast of the Nile to the development of wasteland resources from east to west and expands eastward. The scale is larger than the westward expansion. The urban living environment has instantly changed from the low-dense intensive to the new loose and comfortable and elegant. Shalaby (2012) prominently mentioned that expansion of urban area amounted to $2536.3 \mathrm{~km}^{2}$ during the study period from 1984 to 2006. Urban sprawl is mainly associated with human activities and unorganized management (El-Kawy et al., 2011). Effective efforts should be applied from the Egyptian government for the urbanization problem and the loss of agricultural land in Nile Delta through new reclamation of bare lands around the deserts near to the Nile Delta (Hegazy et al., 2008). Elhag et al. (2013) proposed a good plan for water conservation by preventing the urban sprawl over the fertile lands. Bare lands occupy about 154,031.73 hectares, which is close to one-third of the total area of the study area. It is about $30.20 \%$ of the total area of the study area, with 474 maps. Bare lands are mainly distributed on 
both sides of the Nile Delta, southeast of Cairo City and southwest of Giza City. Bare lands surfaces have gradually become the main reserve for agricultural and urban land. Now, bare lands are closely occupies by urban land, industry, mining and new technology irrigation. The distribution characteristics are typically characterized by the greater fluctuation of the geomorphology and the wider the standard distribution with the water network of the Nile River. Vegetation cover of the study area may be classified into cultivated, garden, wood and grass land. These classes are similar to those used in Raunkiaer's life form classification (Tansley, 1946). The plant taxonomy used by Botanists and Ecologists has not been used because it is based on plant evolution rather than outward appearance. Cultivated land naturally occupies the largest area of vegetation cover in the study area about $127,790.76$ hectares with a percentage $25.05 \%$ of the total area of the study area and 2331 maps. Wood land typically occupies 17,925.60 hectares with a percentage $3.51 \%$ of the total area of the study area and 705 maps. Garden land includes about 17,041.19 hectares, accounting for $3.34 \%$ of the total area of the study area and 884 maps. On the other hand, grass land occupies the smallest are with being 386.32 hectares, accounting for $0.08 \%$ of the total area of the study area. Finally, the total area of vegetation covers in the study area about 127,790.76 hectares, accounting for about one-third of the entire study area. The agriculture lands that distributed around the Nile River are fan-shaped through visual interpretation and remote sensing tools. Ali and El-Magd (2016) stated that the marked decrease in vegetation cover in the Nile Delta typically have a negative impact on the agriculture productivity and its important contribution to the national food security. Deteriorating the productivity of the agriculture cover is mainly due to salinization and salt water intrusion from the sea and shallow ground water level. In the present study, vegetation cover is mostly demonstrated in two unique aspects. It may be equitably distributed around the Nile River Basin. The grassland is sporadic and distributed in the agricultural irrigation land area of the study area, which is mainly formed during the transition period of partial construction land and agricultural land degradation and successful conversion. Surface water area is occupies about 8475.53 hectares, accounting for $1.66 \%$ of the total area of the social study and the number of maps is 291 . The Nile Basin is the only chief source of water for agriculture and cultivation. There are sporadic reservoirs and water surface of the pond. The entire delta is nourished by the Nile River. Its distribution is properly distributed in a fishnet shape from south to north. The excessive enlargements of the fish farms and other aquaculture activities affect negatively on the area of water bodies and cause more degradation to civilized human. Hereher et al. (2010) said carefully that urban sprawl in the Nile Delta also included with the economic expansions of sandy soil. The mining land covers about 2794.43 hectares, accounting for $0.55 \%$ of the total area of the study area, with 18 maps. The main distribution of mines is also very small, but it is distributed on the edge of the city. The development methods are mostly open-air operations, 
which have a great impact on the urban environment, the Nile water environment and the health of surrounding residents. The mines in the study area are mainly distributed in Cairo City and the leading edge of the active construction site on the south side of the chief city of Giza.

\subsection{Landscape Metrics}

Two metrics models were carefully proposed for landscape evaluation; Square Pixel (SqP) and Fractal Dimension (Frac). Fractal Dimension revealed that all the social values were more than one and majority of these cautiously approaching to two values which indicates a marked tendency of more natural forms and get obvious indication about the nature of landscape in the Nile Delta (Table 4). Studies proven that $\mathrm{SqP}$ values were lower than 0.5 is very critical for landscape assessment and investigation. These methods give high indication of urban detection.

\subsection{Spatial Distributions}

The remarkable accuracy of spatial distribution of cities around the Nile Delta of both Kriging and IDW is almost the same. IDW has more simple procedure and fewer steps in direct comparison to Kriging. According to Figure 5, more data may be carefully extracted from IDW giving an accurate data about cities distribution in the Nile Delta. IDW is efficient than Kriging.

On the other hand, reliable information may be developed and applied using Kriging method. The overall accuracy of Kriging method depends on sample points examination. Also, only used for estimating around that particular point, rather than typically assigning a universal distance power value. Moreover, interpolated cells of the boundaries may show using Kriging the as show in Figure 6. Two metrics show the impact of anthropogenic activities on the Nile Delta. El Banna and Frihy (2009) reported that both natural and anthropogenic factors have influenced the Nile Delta coastal area. Among these factors are: change in the Nile sediment supply, coastal processes, land subsidence and deterioration of natural habitats.

Table 4. Landscape metrics in the study area.

\begin{tabular}{ccc}
\hline Class/Landscape & Fractal Dimension Index & Square Pixel Index \\
\hline Cultivated land & 1.123842 & -27.3799 \\
Garden land & 1.132986 & -24.5789 \\
Wood land & 1.154343 & -23.9899 \\
Grass land & 1.477573 & -6.18724 \\
Bare land & 1.687526 & -3.05423 \\
Urban area & 2.399353 & -0.10345 \\
Water bodies & 1.978605 & -1.08672 \\
Mining land & 1.324024 & -9.37834 \\
\hline
\end{tabular}




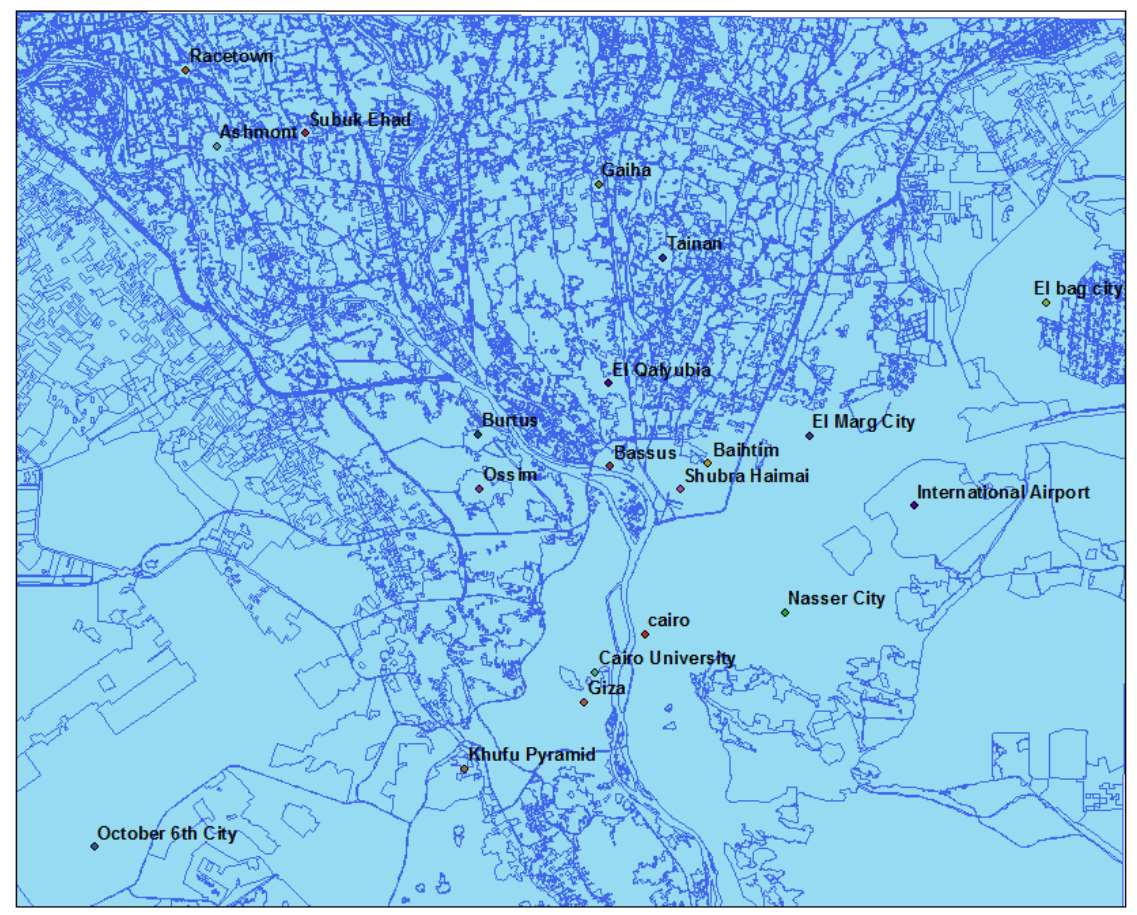

Figure 5. Main cities and major landscapes of the study area.
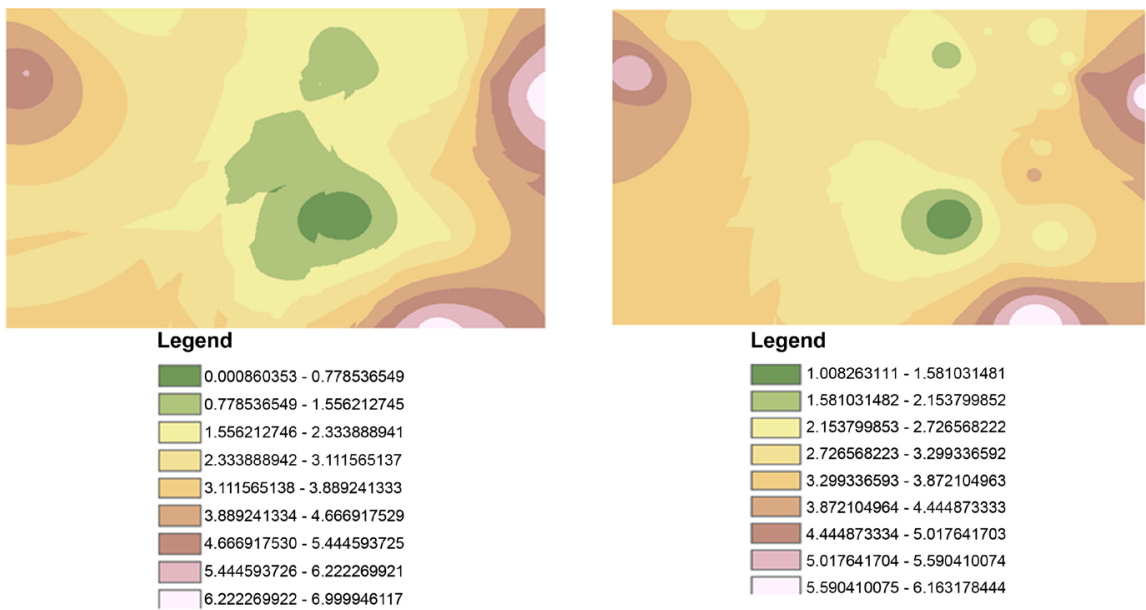

Figure 6. Kriging (left) and IDW (right).

\section{Conclusion}

Visual interpretation and statistical equations using remote sensing and GIS have carefully classified landscapes features of the Nile Delta. The present study had successfully calcified landscapes into: cultivated land, garden land, wood land, grassland, bare land resources, surface water, mine land and urban land in the study area. The urban area occupies the largest, and the mining occupies the smallest area from the study area. The vegetation cover concerned around the Nile Basin depends on the water availability. The soil fertility is a mature irrigated agricultural cultivation area. The expansion of the city toward the desert highlights the relation between the intensity of cultivated land in Egypt and the 
pressure of population growth. The urban expansion model needs to increase the attention and effective prevention of geological disasters such as land desertification and soil erosion.

\section{Conflicts of Interest}

The authors declare no conflicts of interest regarding the publication of this paper.

\section{References}

Ali, E. M., \& El-Magd, I. (2016). Impact of Human Interventions and Coastal Processes along the Nile Delta Coast, Egypt during the Past Twenty-Five Years. Egyptian Journal of Aquatic Research, 42, 1-10.

Belgiu, M., Drau, T. L., \& Strobl, J. (2014). Quantitative Evaluation of Variations in Rule-Based Classifications of Land Covers in Urban Neighborhoods Using World View-2 Imagery. ISPRS Journal of Photogrammetry and Remote Sensing, 87, 205-215.

El Banna, M., \& Frihy, O. (2009). Human-Induced Changes in the Geomorphology of the Northeastern Coast of the Nile Delta, Egypt. Geomorphology, 107, 72-78. https://doi.org/10.1016/j.geomorph.2007.06.025

Elhag, M., Psilovikos, A., \& Sakellariou, M. (2013). Land Use Changes and Its Impacts on Water Resources in Nile Delta Region Using Remote Sensing Techniques. Environment, Development and Sustainability, 15, 1189-1204. https://doi.org/10.1007/s10668-013-9433-5

El-Kawy, O. R. A., Rød, J. K., Ismail, H. A., \& Suliman, A. S. (2011). Land Use and Land Cover Change Detection in the Western Nile Delta of Egypt Using Remote Sensing Data. Applied Geography, 31, 483-494. https://doi.org/10.1016/j.apgeog.2010.10.012

El-Ramady, H. R., El-Marsafawy, S. M., \& Lewis, L. N. (2013). Sustainable Agriculture and Climate Changes in Egypt. In E. Lichtfouse (Ed.), Sustainable Agriculture Reviews. Sustainable Agriculture Reviews (vol. 12, pp. 41-95). Dordrecht: Springer. https://doi.org/10.1007/978-94-007-5961-9_2

Haars, C.A., Lönsjö, E. M., \& Mogos, B. (2016). The Uncertain Future of the Nile Delta. https://www.researchgate.net/publication/301549227

Hegazy, A. K., Medany, M. A., Kabiel, H. F., \& Maez, M. M. (2008). Spatial and Temporal Projected Distribution of Four Crop Plants in Egypt. Natural Resources Forum, 32, 316-326. https://doi.org/10.1111/j.1477-8947.2008.00205.x

Hegazy, I. R., \& Kaloop, M. R. (2015). Monitoring Urban Growth and Land Use Change Detection with GIS and Remote Sensing Techniques in Dakahliea Governorate Egypt. International Journal of Sustainable Built Environment, 4, 117-124. https://doi.org/10.1016/j.ijsbe.2015.02.005

Hereher, M. E., Salem, M. I., \& Abd El-Hamid, H. T. (2010). Change Detection of Salt-Affected Soils at the Coastal Zone of the Nile Delta Using Remote Sensing. Egyptian Journal of Soil Sciences, 50, 111-123.

Reed, J., Deakin, E., \& Sunderland, T. (2015). What Are 'Integrated Landscape Approaches' and How Effectively Have They Been Implemented in the Tropics: A Systematic Map Protocol. Environmental Evidence, 4, 2. https://doi.org/10.1186/2047-2382-4-2

Rocchini, D., Perry, G. L.W., Salerno, M., Maccherini, S., \& Chiarucci, A. (2006). Landscape Change and the Dynamics of Open Formations in a Natural Reserve. Landscape 
and Urban Planning, 77, 167-177. https://doi.org/10.1016/j.landurbplan.2005.02.008

Shalaby, A. (2012). Assessment of Urban Sprawl Impact on the Agricultural Land in the Nile Delta of Egypt Using Remote Sensing and Digital Soil Map. International Journal of Environment and Sciences, 1, 253-262.

Shalaby, A., \& Tateishi, R. (2007). Remote Sensing and GIS for Mapping and Monitoring Land Cover and Land-Use Changes in the Northwestern Coastal Zone of Egypt. Applied Geography, 27, 28-41. https://doi.org/10.1016/j.apgeog.2006.09.004

Tansley, A. G. (1946). Introduction to Plant Ecology. London: George Allen and Unwin.

Topaloglu, R. H., Sertel, E., \& Musaoglu, N. (2016). Assessment of Classification Accuracies of Sentinel-2 and Landsat-8 Data for Land Cover/Use Mapping. Proceedings of the XXIII ISPRS Congress International Archives of the Photogrammetry, Remote Sensing \& Spatial Information Sciences, XLI-B8, 1055-1059.

https://doi.org/10.5194/isprs-archives-XLI-B8-1055-2016

Turner, M. G., Gardner, R. H., \& O’Neill, R. V. (2001). Landscape Ecology in Theory and Practice: Pattern and Process. New York: Springer Verlag. 